\title{
LAS HISTORIAS DE VIDA \\ Y LAS CIRCUNSTANCIAS DE ELOCUCIÓN
}

Perla Petrich

Universidad de París

En el espacio de este artículo intentaré llevar a cabo una reflexión sobre una serie de historias de vida obtenidas durante trabajos de campo realizados en la zona de Chiapas en México y el lago Atitlán en Guatemala. Dicha reflexión encontrará su justificación en una serie de postulados teóricos referidos fundamentalmente a los procesos de interlocución.

\section{Temática y metodología}

La temática ofrece una relativa coherencia: las narraciones pertenecen a indígenas de origen maya, todos ellos "curanderos" cuya influencia y prestigio terapeútico varían según la edad y el lugar donde ejercen sus actividades.

Por el contrario, los lineamientos metodológicos que guían mi reflexión son más difíciles de encuadrar, ya que en este caso no se trata de recoger datos objetivos y precisos con vistas a una descripción, sino de interpretar un discurso originado en una comunicación puramente oral. Situación que implica la presencia del investigador y de un interlocutor.

Limitado, el contacto con el otro dependerá del circuito de la palabra y de la memoria selectiva y subjetiva del interlocutor quien, por lo general, se referirá a hechos difíciles de identificar y situar en una red social que el investigador no conoce bien y de la que, hasta ese momento o poco antes, no formaba parte. El resultado será un testimonio de experiencias individuales. Por una parte, una elocución ya construida, 
puesto que sobre determinados temas cada individuo tiene más o menos elaborada una opinión fija y coherente. Por otra, una elocución variable, dinámica, consecuencia de una relación de interlocución donde cuenta el hecho de hablar ante la presencia del investigador, responder a sus preguntas y reaccionar a sus comentarios. En otras palabras, decir o callar según la impresión que el investigador ha causado, según "la idea" que el locutor se ha forjado de él.

¿Cómo tratar el material resultante? Difícil delinear un método preciso. Posible buscar algunas vías de acercamiento y proponer desplazamientos de focalización, paulatinos movimientos de descentralización que se orientan no solamente hacia los discursos obtenidos, registrados y guardados cuidadosamente en el cuaderno de notas o en la grabadora, sino, sobre todo, a los procesos de comunicación que los hicieron posibles.

\section{La elocución productora de sentido}

Si admitimos que la lectura o audición integral de los discursos recogidos durante el trabajo de campo nos permite restituir sólo una parte de lo que significaron en el momento de la elocución, podremos suponer que es en el espacio dinámico de la producción de la palabra donde puede encontrarse el contenido complementario, indispensable para aprehender la totalidad del mensaje.

Las palabras que hemos atesorado cuidadosamente en cada entrevista se encuentran fuera de contexto. No son sino una manifestación estática, amputada de voces y gestos, risas, tonos e intenciones supuestas. Las frases se encadenan, pero con zonas vacías, con ranuras imposibles de rellenar si nos encerramos en la inmanencia de esos discursos.

Ante la situación anteriormente descrita, dos posibilidades parecen viables: la primera, reduccionista, consiste en suponer que los discursos registrados son suficientes. La ausencia de informaciones contextuales en relación con el emisor y con su medio ${ }^{1}$ no son un impedimento para la interpretación.

La segunda posibilidad supone aceptar la duda: duda sobre la posibilidad de limitar la significación - la realidad del interlocutor- a enunciados fosilizados en una semántica inamovible que no acepta más que la irreductibilidad de lo dicho. Duda, fundamentalmente, sobre el

\footnotetext{
${ }^{1}$ Conocimiento definido por Kerbrat-Orecchioni (1986: 7) como "enciclopédico".
} 
sentido de los datos recogidos; posibilidad de que el entrevistado, al ser consultado dos meses más tarde, niegue categóricamente lo que nos afirmó con vehemencia; que el descubrimiento de un ignorado lazo familiar entre nuestro interlocutor y un miembro de la comunidad ponga en tela de juicio la interpretación que realizamos de su discurso; que motivaciones, deseos, temores que ignoramos le hicieran contradecirse, disimular, ocultar, mentir o adoptar posiciones incoherentes que cambian apenas nosotros - los observadores externos- desaparecemos de la escena y no constituimos más un obstáculo intermediario entre "él" y "su" mundo.

Si nos inclinamos hacia la segunda posibilidad, dos puntos de reflexión retienen nuestra atención: la situación de interacción individual $\mathrm{y}$ las estrategias individuales.

\section{Situación de interacción}

Nuestros encuentros con la persona que nos interesa conocer se incluyen en las relaciones sociales y, en consecuencia, pueden provocar las mismas reacciones que se comprueban en toda situación interpersonal. En efecto, cada uno de los actores que forman parte de la encuesta (etnográfica, lingüística, etc.) es susceptible de elecciones, iniciativas y estrategias (Ansart, 1990: 217). En dicha situación, los papeles que cada protagonista asume y que, al mismo tiempo, atribuye al otro, son un factor de suma importancia. Al establecer una relación -única porque la combinación de los sujetos es irrepetible-me tipifico y, al mismo tiempo, tipifico el papel del otro y visceversa (Chutz, 1987: 25). Esta tipificación me lleva a anticipar su comportamiento: si le atribuyo un papel, le adjunto necesariamente una supuesta forma de actuar. Lo mismo hace mi interlocutor. Esta "idealización de motivos recíprocos" (Chutz, 1970: 30) es una causa de equívocos permanentes, pues mi acción - como la suya - suponen una serie de "proyectos" anteriores que desconocemos mutuamente: el otro no sabe qué ha precedido a mi acción; no sabe por qué estoy ahí. Desconoce mis intenciones y el contexto en que han podido inscribirse. Sólo puede, a partir de su contexto - de lo que él sabe y conoce-, incluirme en alguno de sus proyectos. Yo ignoro la idea que el otro se hace de mí y el papel que me atribuye; sólo puedo suponer a partir de lo que me resulta accesible y lo accesible, lo cierto y tangible no va mucho más allá de un presente observable: yo y él frente a frente. 
Otro aspecto que se agrega a la ambigüedad de la relación interpersonal establecida es el de su finalidad. Chutz (1970: 33) señala una diferencia importante: la implicación del observador (en ese caso el investigador) es mínima, porque su interés no es práctico sino cognoscitivo; la situación que observa y analiza no constituye su campo de actividades, sino su objeto de contemplación.

La división de Chutz nos parece interesante no para aceptarla en forma categórica, sino para comprobar que la establece teniendo en cuenta únicamente el punto de vista del observador. Si consideramos lo que el otro se imagina del investigador descubriremos que, generalmente, le atribuye una finalidad práctica y muy pocas veces cognoscitiva: piensa que viene a recoger datos para luego publicar libros con los que ganará mucho dinero; que busca información para entregársela al ejército, que quiere convertirlo a una secta protestante, o simplemente pretende comprar tierras, etc. El temor a una agresión exterior y la tendencia a protegerse frente a un desconocido que lo interroga son reacciones que influyen definitivamente en sus informaciones. ¿Es posible en esas circunstancias desinteresarse de la representación que la persona entrevistada elabora sobre el entrevistador y sus intenciones? $\mathrm{Y}$ aún más: ¿es posible no tener en cuenta la mayor cantidad posible de factores que influyen directa o indirectamente en la interlocución?

\section{Las estrategias individuales}

Trayectorias indeterminadas. En primer lugar debemos tener en cuenta que cada persona que contactamos ha desarrollado estrategias que se inscriben en conflictos anteriores a nuestra llegada. Una presencia extraña - la nuestra- supone un cambio de situación y, en consecuencia, una nueva conducta por parte del individuo. Nosotros intervenimos, muchas veces sin saberlo o quererlo, como una pieza a través de la cual se elaboran nuevas estrategias: "trayectorias indeterminadas" (De Certeau, 1990: 57) con las que el sujeto pretende solucionar sus conflictos y, en última instancia, obtener "la conquista de la legitimación" (Ansart, 1990: 107) dentro de su propio grupo. De manera consciente o inconsciente el individuo piensa que la presencia del "extranjero" marcará una diferencia cuantitativa en su existencia: el interés que el antropólogo demuestra por sus actividades, por ejemplo, será generalmente interpretado como una forma de admiración por sus conocimientos y así lo hará saber a los vecinos. De este modo supone que estable- 
cerá o aumentará su "prestigio" local y obtendrá pacientes si es curandero o adhesiones si aspira a un puesto político o administrativo. Estas tácticas y sus finalidades, por lo general, falsean o al menos modifican en gran medida las informaciones.

Las representaciones personales. En segundo lugar hay que tener en cuenta que las informaciones del sujeto, aun en el caso de que no sean falseadas expresamente, corresponden a la visión indefectiblemente personal y limitada que posee del universo social donde se encuentra inscrito. Al definir las prácticas, por ejemplo, lo hará desde "su" posición. En otras palabras, sus intereses determinan una visión parcial y subjetiva de la realidad. Se plantea en ese caso lo que Ansart (190: 168) califica como "problema de las relaciones entre las representaciones subjetivas de los agentes y sus relaciones objetivas".

Referentes personales. Un tercer aspecto importante es que dentro de una sociedad en proceso de cambio las representaciones tienden a individualizarse mucho más que en el caso de una sociedad relativamente estable. En los proceso de transición se fragiliza o desaparece la uniformidad de actividades, agrupaciones socioculturales, creencias, etc. Los estereotipos comunitarios se debilitan y se afirman los referentes personales. Cada información está cargada de particularidades cuyo sentido se nos escapa por nuevas, imprevisibles e incoherentes. En estas situaciones el papel social del individuo está atomizado, varía en los diferentes papeles que asume, en primer lugar, según el interlocutor y la representación que de él posee el sujeto $y$, en segundo, según las circunstancias personales y su propia historia. De este modo frente a la creencia puede asegurar, según crea conveniente, que es católico o protestante; profesionalmente puede asumir el papel de agricultor tradicional o adoptar como definitiva una actividad que, por lo general, es ocasional, como la de "jardinero" o "albañil".

Ante el calidoscopio de posibilidades múltiples el investigador ignora el porqué de la elección de un papel; papel que supone discursos, juicios, inclinaciones y decisiones que resultarán contradictorias con las que el mismo individuo asumirá dentro de otro de sus posibles papeles sociales. En muchos casos se trata de particularidades y reivindicaciones que le son propias y que se refieren sólo a una minoría socioprofesional (promotor de salud, maestro, etc.), religiosa (acción católica, secta protestante, etcétera). 
La retórica del discurso. El cuarto y último aspecto es el que se refiere directamente a las posibilidades de recepción y comprensión de un enunciado teniendo en cuenta la retórica misma del discurso.

Hay dos aspectos que nos parecen fundamentales: los presupuestos y los implícitos. "Capas" del discurso que exigen por parte del receptor un conocimiento de la realidad extraverbal, es decir, de elementos contextuales. En el primer caso, el de los presupuestos, se supone que el receptor del discurso conoce realidades, hechos, situaciones a las que hace alusión en el discurso pero sin detallar o explicar. En este caso la ausencia de un "conocimiento encilopédico" por parte del investigador impide la comprensión del discurso o determina su mala interpretación.

Los implícitos pertenecen a un registro más afectivo y por lo general se recurre a la elipsis, a los gestos, a las frases inconclusas o de dole sentido: una frase sin terminar seguida de un largo silencio como "y ustedes los que vienen de afuera siempre tienen su platita, no es como nosotros..." implica que el locutor está esperando que se le ayude con un poco de dinero.

Otro aspecto interesante para tener en cuenta es el de la constitución formal del discurso, el de su mecánica de construcción: discurso espontáneo sin secuencias organizadas, discursos con secuencias fijas (relato mítico, parlamento político, etc.), discursos con secuencias móviles y adaptables, etcétera.

\section{Estudio de casos}

Mis trabajos de campo se han desarrollado en México y en Guatemala orientados, por lo general, hacia temas en los que se manifiestan las situaciones de cambio que viven los grupos indígenas de origen maya. Dentro de esta línea de investigación contacté a varios curanderos y me interesé en sus historias de vida. Presentaré tres casos intentando en cada uno poner de manifiesto un aspecto teórico.

Un curandero mexicano: el discurso como estrategia de legitimación

El contexto es Motozintla en Chiapas, donde está instalado el grupo maya conocido como mochó, que no cuenta actualmente con más de 200 hablantes de la lengua vernacular: el motozintleco o mochó. 
Los mochós están diseminados en barrios periféricos, con lo cual prácticamente han desaparecido las posibilidades de cohesión cultural y política, esta última en manos de los mestizos. Una sola fiesta anual reúne aún al grupo. Desde hace unos 20 años todos los niños están escolarizados. Los hombres trabajan tierras comunitarias donde cultivan maíz y frijol para la subsistencia y café para la venta. La mayoría incursiona en trabajos asalariados más o menos estables, como el de albañiles o peones en los cafetales de la costa.

$\mathrm{La}$ vida religiosa se comparte entre las creencias tradicionales y el proselitismo indiscriminado ejercido tanto por la Iglesia católica como por las sectas y denominaciones protestantes.

En relación con los servicios sanitarios, existen un hospital, varios dispensarios y numerosos enfermeros que se desplazan a domicilio y ofrecen sus servicios (inyecciones de "suero" y "vitaminas") por módicos precios y compiten con los pocos curanderos que ejercen cada vez con mayores dificultades económicas sus funciones. En este contexto debemos ubicar a Julián Ramos, un hombre casado con siete hijas mujeres. Cuando lo conocimos tenía 55 años y su autoridad como curandero disminuía día a día a causa, por una parte, de las nuevas terapias señaladas y, por otra, por sus frecuentes borracheras, que le hacían descuidar y perder a los pacientes.

Inesperadamente la aparición de extranjeros modificó notablemente su situación, no en un nivel práctico pero sí en la realidad imaginaria: que alguien demostrara interés por sus conocimientos le permitió sentirse depositario del patrimonio cultural mochó. Tomó conciencia de ser uno de los únicos mochós cuya memoria era capaz de reconstruir un mundo que a su alrededor se modificaba y desaparecía. Ilusoriamente vio la posibilidad de recuperar su prestigio y volver a ser, como antes, arbitrio de todas las decisiones importantes. Al preguntarle sobre su vida, me relató lo siguiente:

... en aquellos tiempos yo cuando nací mis padres eran muy pobres. Apenas conseguíamos maíz... mi madre nos daba de comer apenas guineo con frijol, sin tortillas. Pasábamos hambre. Nuestro pantaloncito era pura jilacha, todo remendadito. $\mathrm{Y}$ así fuimos creciendo hasta que llegué a joven pero pobre y sin saber nada de las escrituras, porque cuando venían los profesores mi mamá y mi papá decían: "ahí vienen los escueleros, ahí vienen los maestros, retírense". Nosotros salíamos corriendo y nos quedábamos acurrucaditos en el monte. Ya cuando se iban nos veníamos y ya nos íbamos a traer leña. No había estudio, nada y así fuimos creciendo porque ni los padres mismos sabían ni leer ni escribir. Cuando llegué a joven, así de 
pobre, le hablé a ella, a saber cómo me quiso, pero de ahí la suerte. Ya de repente después de juntados como dos años, me fui a la finca, ${ }^{2}$ comencé a luchar para hacer mi casa, conseguir dinero, todo. Dos años fui a la finca, pero ya de repente me enfermé de ataque, me caí en el barranco... mi sombrero perdí en el cerro, mi mecapal, mi costal. Claro, ya volvía yo sin nada y entonces ella, mi señora, iba a preguntar a los curanderos. Ellos le decían: "su marido tiene saber, esté tranquila, va a sanar, no tenga miedo, la cosa cura". Entonces ella, como era lista, comenzó a comprar lo que servía. Yo ni cuenta me daba de tan enfermo que estaba. Mi mujer me decía: "vos vas a ser curandero" y yo le contestaba: "Tal vez, tal vez Dios me va a ayudar y voy a saber rezar y curar". Al tiempo me entregaron la cruz, ${ }^{3}$ mi destino. Recibiendo mi cruz, claro está que sané y pude curar a la gente; yo les digo lo que les hace bien, los aconsejo, los defiendo. Ésa es mi vida.

A través de este discurso se observa que la forma en que cada vida se convierte en relato es ya una respuesta a la situación conflictiva en la que el individuo se encuentra: Don Julián cuenta su vida seleccionando los recuerdos que le permiten presentar su actividad de curandero como una actividad prestigiosa. La estructura formal es la de un mito y si aplicamos el esquema de Propp ${ }^{4}$ descubrimos que encaja perfectamente dentro de este tipo de relato: una situación negativa inicial (pobreza, analfabetismo), cumplimiento con éxito de una serie de pruebas calificativas que le otorgan competencia (trabajo en las fincas cafeteleras, casamiento) y luego superación de la prueba principal (enfermedad iniciática) de la que el sujeto sale victorioso gracias a la participación de un ayudante (la mujer) y un objeto mágico (la cruz).

Lo que el emisor trata de hacer al contar su vida es utilizar el discurso como estrategia de legitimación: al presentarse como un "héroe" busca ser valorizado de esa manera frente a los demás. El relato, perfectamente elaborado y recitado sin vacilaciones, es una forma de compensación de su situación, una proyección imaginaria de sus deseos. Por otra parte, inconscientemente sabe que ése es el tipo de discurso que me interesa porque le he pedido con frecuencia que me cuente mitos. Al principio objetaba "haber olvidado todo porque ya a nadie le interesaba" y poco a poco, en un contexto de interlocución

\footnotetext{
${ }^{2}$ Fincas cafetaleras de la costa del Soconusco.

${ }^{3}$ Todo curandero debe poseer una gran cruz de madera que le es entregada como signo de confirmación por los otros curanderos. Esta cruz es de origen católico, pero se le adora disociada del Cristo. Hasta la actualidad algunos grupos como los yucatecos le atribuyen poderes oraculares.

${ }^{4}$ Vladimir Propp, Morfología del cuento maravilloso.
} 
propicio, los recuerdos "volvieron" y fue al contarlos y escucharlos repetidas veces en la grabadora: ese hombre creyó recuperar un auditorio y con él su prestigio.

\section{La mujer del curandero: retórica de implícitos y discurso espontáneo}

Cuando Julián nos contó su historia de vida, estaba presente la esposa. No interrumpió ni hizo ningún comentario cuando éste terminó pero, al preguntarle por su propia vida, habló de la de su marido:

Él se encarga de la siembra; vendiendo su cafe ${ }^{5}$ y curando gente gana alguna platita. Curando gente gana sólo un poquito porque los Espíritus de él no quieren que cobre. Yo lavo ropa ajena: treinta pesitos y vendo mis tortillas y así cincuenta pesos diarios, con eso me voy a comprar verduritas en el mercado y me voy en camión a Belisario y ahí vendo todo; si tengo suerte traigo entre doscientos pesitos y así vamos pasando y tengo ahorrado algún dinerito y él [el marido] su único dinero es el del café. Una vez al año junta alguna platita. Aquí [señala el huerto de la casa] también vendemos algunas naranjas y algunos limones. Mi hijo sí... es albañil, gana sus mil pesos por semana pero él [su marido] no tiene ningún trabajo afuera, no le gusta, vaya a saber por qué... él así va pasando los días... limpiando su milpa, haciendo un corralito.

El discurso de la mujer no se encasilla dentro de ningún modelo narrativo, puesto que ella no está acostumbrada a contar historias. Sus palabras son espontáneas, marcadas por deíxis temporales y espaciales que ubican el relato en el presente y en el lugar concreto del pueblo y de la casa. Este relato, interrumpido por pausas y titubeos, presenta una versión contraria a la del marido y nos permite completar el personaje del curandero. En efecto, el primer discurso nos presentaba a un héroe mítico sin fisuras; la mujer lo humaniza y muestra su inadaptación a los cambios: incapaz de aceptar un trabajo asalariado o de aportar dinero por otros medios, hace recaer en ella tales obligaciones. A través de frases inconclusas deja entrever implícitamente que no valoriza positivamente al marido: "Mi hijo sí... es albañil" es una frase que supone que su hijo no es irresponsable como el padre.

${ }^{5}$ La cantidad de café era mínima: dos o cuatro costales. 


\section{Dos curanderos de Guatemala}

En Guatemala tuvimos una nueva experiencia: encontramos otro tipo de contexto y dos casos diferenciados, ante todo, por la edad: Amadeo López, de 30 años, y Andrés Chial, de 80 . Ambos de origen cakchiquel, pero habitantes de pueblos diferentes en el lago Atitlán. ${ }^{6}$

La violencia generada en estos últimos 10 años a causa de la acción de la guerrilla y la represión del ejército ha provocado en la gente un síndrome del miedo que se manifiesta en una desconfianza muy marcada frente a cualquier desconocido.

Por otra parte, las Iglesias protestantes ejercen una acción proselitista indiscriminada: encuestas de carácter sanitario, educativo, etc., suelen ser pretextos para intentar convertir a las familias. El éxito es evidente y en ciertos pueblos se observa una conversión de más del $60 \%$ de los habitantes. Esa situación ha creado una total atomización de creencias y una duda permanente sobre la veracidad de lo creído. Toda información referida a las creencias tradicionales está generalmente precedida de la fórmula: "No sé si es cierto, a mí me lo contaron". Muy poca gente se asume emisor de un discurso; por lo general se recurre a una tercera persona impersonal e imprecisa: "hay quienes dicen que"...; "todavía algunos creen que..."; "se dice que..." Aún menos son los que se aceptan creyentes del contenido de las historias tradicionales. Cada vez que se pregunta: "¿Usted cree en eso?", el interlocutor responde con otra pregunta: "¿Y vos creés?" Con lo cual la siguiente respuesta está de antemano condicionada.

Otra presencia extranjera frecuente es la de organismos de ayuda humanitaria; suelen aportar cambios cuantitativos y cualitativos importantes para ciertos pueblos y ello con la colaboración de miembros del grupo que son seleccionados entre los habitantes que han dado pruebas de poseer una "actitud progresista".

Otro aspecto importante es la situación de cambios acelerados que vive esta region: por su belleza natural se le ha convertido en un centro turístico, y Panajachel, uno de los pueblos del lago, se ha vuelto un verdadero complejo de hostelería destinado a albergar a extranjeros. Muchos indígenas de allí y de otros pueblos trabajan como camareros, jardineros, etc., y diariamente están en contacto con gente de otras nacionalidades a las que, indefectiblemente, admiran por su solvencia económica y observan con curiosidad en su forma de vestir y comportarse.

${ }^{6} \mathrm{El}$ lago Atitlán cuenta con unos 12 pueblos en sus orillas. El $90 \%$ de la población es indígena: maya cakchiquel y maya tzutujil. 
La situación de un antropólogo en este contexto es delicada porque los pobladores lo incluyen necesariamente en alguna de las categorías: turista, representante de una secta, de un organismo humanitario; espía del ejército o potencial comprador de un terreno para construir una casa de veraneo en la zona. A su vez, según el papel que suponen que cumple el extranjero, ellos se invisten del que les parece concomitante. La gama es amplia y depende además de situaciones y necesidades internas. Por estos motivos cada uno de los individuos que se conozca puede definirse, al mismo tiempo, por varias actividades: pescador, agricultor, albañil, comerciante, promotor social, camarero o jardinero en los hoteles, comisionista, etcétera.

De este muestrario de profesiones se excluye, al menos ante un extranjero, la de curandero. Sin embargo, el curandero ocupa un papel importante dentro de los pueblos. Resulta difícil identificarlo porque la gente, temerosa por los motivos que hemos evocado anteriormente, niega su existencia. Piensan que el extranjero, si tiene la intención de convertirlos, los asociará con brujos y, si pertenece a un organismo humanitario, los catalogará de "salvajes atrasados". En mi caso fue recién durante una tercera estadía que pude comprobar la existencia de curanderos y entrevistarlos. Hasta entonces todos me habían asegurado que "ya no había más y eso desde hacía tiempo".

Un joven curandero del lago Atitlan: el discurso móvil. En este sentido el caso de Amadeo es muy significativo: lo conocí durante mi primer trabajo de campo en Santa Catarina. El contacto se estableció a través de su hija, quien había colaborado haciendo dibujos para ilustrar mitos relacionados con el lago. La inteligencia de esa niña de ocho años me había sorprendido mucho y fue una de las primeras cosas que le dije a su padre. Insistí mucho sobre la importancia de que la niña no abandonara la escuela ${ }^{7}$ y continuara estudios después de terminar la escuela primaria. Este hecho determinó un tipo de relación particular: Amadeo, convencido de que yo me interesaba por problemas educativos, intentó por todos los medios demostrarme que él era una persona ilustrada. Todas sus conversaciones estuvieron orientadas en esa dirección: los datos que pude obtener y comprobar fueron que era pescador, aunque no se trataba de su única ni principal actividad; además se dedica-

\footnotetext{
${ }^{7}$ Por lo general a las niñas se les envía a la escuela dos o tres años nada más; apenas como para que aprendan a hablar el español y algunos rudimentos de lectura y escritura. Los varones actualmente llevan a cabo estudios un poco más prolongados, ya que es una condición para conseguir trabajo asalariado posteriormente.
} 
ba a "comerciar" (nunca supe qué), estaba construyendo a la orilla de su casa un albergue "para turistas" y era promotor de salud. ${ }^{8}$ Esta última actividad era la que consideraba de mayor prestigio: se ocupaba de poner inyecciones y daba consejos de higiene a los vecinos. "Todo eso -me explicaba- porque la gente de aquí es muy ignorante y no se dan cuenta de nada." Además tenía como función orientar sobre las posibilidades de control de natalidad: entregaba a las personas que se lo pedían preservativos y pastillas anticonceptivas. Me aseguró categóricamente que su mujer tomaba pastillas porque "no querían tener más hijos para poder pagarles una buena educación a los que ya tenían" (posteriormente confirmé que no era cierto: que ni ella ni ninguna mujer indígena del pueblo aceptaba esa forma de anticonceptivo). ${ }^{9} \mathrm{Me}$ mostró fotos del curso de promotor social que había hecho en los Estados Unidos (seguramente patrocinado por un organismo estadounidense) junto con un grupo de indígenas de la zona. La influencia de esa estadía había sido inmediata, pues los dos hijos varones que habían nacido después de su regreso se llaman: Walter y Nixon.

Aparte de estos datos sólo logré que me contara dos historias tradicionales que ilustró con mucho placer. Escuchaba la grabación varias veces y satisfecho daba el visto bueno diciendo: "Esa historia ha quedado muy bonita".

Nuestra relación se consolidó con mi visita del año siguiente: las entrevistas siempre se llevaban a cabo en su casa y en presencia de su mujer y los niños que participaban con gran entusiasmo. Para mí, Amadeo representaba la nueva generación de jóvenes deseosos de alcanzar un bienestar económico que, necesariamente, se obtenía con un mayor nivel de educación. Su casa era la prueba: una licuadora (que seguramente no usaba jamás aunque él aseguraba que servía para prepararle "jugos" a los niños), una radiocasetera, una heladera (vacía salvo un

${ }^{8} \mathrm{El}$ promotor de salud es alguien a quien se le han impartido cursos elementales de higiene y nutrición; su función es informar a la gente y prestar servicios de primeros auxilios, por ejemplo en el caso de diarrea, amibas, heridas leves, etc. Cuentan con medicamentos de base que deben distribuir entre la población gratuitamente. Suelen aprovechar su prestigio y conocimientos para ganar un poco de dinero (cobrar por poner inyecciones; vender los remedios, etcétera).

${ }^{9} \mathrm{El}$ rechazo a todo medio mecánico o químico de anticoncepción se debe a la necesidad de tener muchos hijos porque la mortalidad infantil es importante. Los hijos constituyen el único capital de la pareja: son ellos los que se encargarán de la subsistencia de los padres ancianos. La imaginación colectiva ha creado múltiples representaciones para afirmar el rechazo; una de ellas es que las pastillas anticonceptivas no se digieren, y entonces se forma una bola en el estómago. En esos casos hay que operar a la mujer para evitar su muerte. 
manojo de hierbas, un trozo de pescado y una botella de "agua natural" a la que mi amigo declaraba ser muy adepto).

Al tercer año me encontré con una situación diferente: la niña había abandonado la escuela y se dedicaba diariamente a la venta de artesanías. Amadeo me aseguró con tono doliente y, al mismo tiempo rencoroso, que era a causa de su suegra que había dicho que la niña ya era grande para seguir en la escuela. Era fácil adivinar que la causa verdadera era que el padre había decidido que abandonase la escuela porque la aportación de la niña era muy importante para el presupuesto familiar. Otra novedad fue que Amadeo más de una vez me recibió diciendo que le dolía mucho la cabeza porque la noche anterior había estado bebiendo. Por su actitud era fácil comprobar que la noche se había prolongado hasta el mediodía.

Tres hechos más marcaron un cambio en nuestras relaciones. El primero fue el paso durante mi ausencia de un alumno mío que le dejó una caja de remedios incluyendo una botella de desinfectante y un termómetro. Además de prometerle el envío de otro tanto por correo desde Francia, le informó sobre la existencia de diversos instrumentos de diagnóstico. El segundo fue el hecho de verme en reiteradas oportunidades hablando con un joven que, después lo supe, se consideraba en el pueblo como un comisionista de terrenos. El tercero fue el contacto que establecí a través de este joven "comisionista" con una anciana comadrona curandera que resultó ser la madre de Amadeo.

Estos tres factores cambiaron mucho las cosas: Amadeo, asesorado por las informaciones "técnicas" que le dio mi alumno, se planteó la posibilidad de que yo también pudiera abastecerle de remedios e instrumentos médicos. Discretamente comenzó a insinuarme que en mi próximo viaje le trajera un aparato para tomar la presión para "conocer rapidito cómo le anda el pulso a esta buena gente" y un estetoscopio para "sentir los ruidos que uno tiene adentro y saber si algo funciona mal". Otro papel que me atribuyó fue el de potencial compradora de un terreno — con lo cual él, automáticamente, asumía el de comisionista-. A partir de ese momento cada encuentro terminaba, indefectiblemente, con el ofrecimiento de una casa o un terreno en venta. Suponía que yo quería comprar algo e intentaba convencerme.

El hecho más decisivo fue la relación que establecí con su madre. Cuando le pregunté con sorpresa por qué nunca me había dicho que tenía una madre y que era curandera me contestó: "Vos nunca me lo preguntaste". La respuesta se adecuaba perfectamente a la circunstancia y, además, respondía a la relación que existía entre nosotros. En 
otras palabras, él nunca se imaginó que pudiera interesarme la medicina tradicional. Una vez que comprobó que no era así y que las actividades de su madre retenían toda mi atención y que además mi actitud era admirativa, Amadeo adoptó un nuevo papel y me atribuyó otro correlativo: la de alguien que podía comprender sus aspiraciones íntimas.

Su madre adivinaba con piedras ${ }^{10}$ a las que consideraba dotadas de un poder oracular. Se acompañaba además — como todo curandero tradicional- con el incienso, las velas, los rezos y las hierbas. Amadeo siempre estaba presente en nuestros encuentros. Una tarde, después de haber visitado juntos a su madre, me dijo: "cuando las personas vienen a verme yo también tengo que llamar a Dios; tengo que presentarme y presentar a mi paciente con incienso y con candela y eso tengo que hacerlo con una oración original de antiguo, igual como hace mi mamá. Ésa es una muy bonita costumbre, sí, muy bonita". Inmediatamente me anunció que él también tenía sus piedras y que si yo quería me las podía mostrar. Y así fue efectivamente: fuimos hacia su casa y de un rincón trajo una caja y ante mi gran sorpresa la abrió y me mostró lo que había adentro: piedras de diferentes tamaños y formas; incluso algunas precolombinas que había encontrado cavando en la milpa. Un trozo de vidrio blanco en forma de lágrima - posiblemente proveniente de un lustro roto- cumplía la función de la piedra de cuarzo. ${ }^{11}$ Acariciando sus piedras, me explicó:

Uno encuentra las piedras, cabal así nomás por donde ande. Ésa es su suerte. Las piedras salen solitas. Uno se va al monte y ahi pepena las piedras. A veces yo pepeno unas bien bonitas; a veces tienen cara y a veces no. Si uno consigue amontonar bastantes es mejor. De todos modos hay que juntar las piedras. Las piedras no se buscan... saber por qué será, pero uno mira por debajo de la tierra, uno escarba un poquito y ahí están. Uno por suerte puede encontrar mientras trabaja la milpa o la cebolla. Uno no puede comprarlas porque entonces ya no es verdad lo de su suerte. Si uno tiene suerte debe pepenarlas. Todo buen curandero recoge piedras, una o dos cada año, $y$ eso mientras viva. Para saber si hablan hay que examinarlas bien. Mi mamá dice que habla con las piedras como si fueran personas. Yo todavía no muy puedo pero a veces sí, como que ya comienzo a oír que me están hablando. Porque eso te digo a vos para que sepas: las piedras no son mu-

${ }^{10}$ Cada curandero posee una cantidad importante de piedras de tamaño regular que coloca juntas sobre su altar. Cuando un enfermo viene a verlo él se arrodilla ante las piedras y las "consulta" para determinar cuál es el origen del mal y cuál es el tratamiento adecuado.

${ }^{11}$ La piedra de cuarzo es indispensable para la consulta oracular; es la piedra central, la que posee más poder. 
das. No, pues, si uno no las oye es porque ellas se están calladas, porque no tienen ganas de hablarnos y eso porque todavía no estamos bien maduros, todavía nos falta crecer, todavía nos falta prepararnos para saber escucharlas. Las piedras son como raíces, como raíces del mundo.

A partir de ese día su discurso se orientó hacia la defensa de los tradicionales $\mathrm{y}$, habiendo confirmado mi aversión inequívoca hacia los grupos protestantes, fue contra ellos que orientó sus ataques:

La gente con la entrada de los evangelistas ya se olvidaron de sus costumbres; ya no quieren más. "Ahora ya todo está muy caro y no hay necesidad", eso dicen para que ya no hagamos las fiestas como antes. Esos evangelistas es puro canto y puro zarandearse pero en el lugar. Yo no, yo sigo queriendo las fiestas de nosotros, la de nuestro pueblo, las de siempre, por eso yo me encargo del baile de los Negritos. ${ }^{12}$ Yo mismo hago las máscaras y cuando llega la fiesta los muchachos me las piden y se las ponen. También traemos marimbistas pero todo eso está muy caro; por eso la gente ya no muy quiere, no pueden colaborar y eso es lo que necesitamos. Cuando uno los llama ellos dicen "está bien" pero después no cumplen. No entiendo mucho por qué los evangelistas piden más, como un diezmo semanal y ellos lo dan ¿por qué? Ellos dan bastante dinero. Será porque como allí les prohíben a la gente que tomen trago entonces ya les alcanza... pero es bonito eso de poder tomarse unos traguitos... uno es hombre y bien que le gusta... no entiendo... eso también es bueno. Yo tomo de vez en cuando. No mucho porque chupando... chupando después ya no puede mantener a la familia. Si uno le da a la tomada de nada sirve la secta porque fijate vos que mi hermano bien que era de los adventistas y, como si nada, porque sigue chupa que chupa y dándole golpes a los güiros y a la mujer.

Fue entonces cuando le pedí que me contara la historia de su vida:

Desde chico me fui a buscar leña y a hacer mandados. De pequeño me mandaron a la escuela pero ya era medio grande, ya tenía como mis 12 años. Me estuve poco y en cuanto mi papá vio que ya podía hablar castellano, me dijo: "ya está bueno, ahora nos vamos al monte". "Está bueno", le dije yo. Y me fui a hacer tablones, ${ }^{13}$ a sembrar cebollas. Poco a poco empecé a irme a pescar. Un poco regaba la cebolla, otro pescaba. Cuando ya estuve grande, él me dijo: “¿te querés casar?" Ya estás grande, si querés yo

${ }^{12}$ El "baile de los Negritos" es un baile que se realiza durante las fiestas tradicionales (la del Santo Patrono, por ejemplo): los hombres se pintan la cara o se ponen máscaras para bailar.

${ }^{13}$ Los "tablones de cebolla" son canteros delimitados con tablones en los que se plantan cebollas a la orilla del lago. 
te voy a ir a pedir tu mujer". Yo no muy sabía, pero "está bueno" le dije. Yo no conocía a ninguna, yo no salía a la calle, yo no era callejero, yo respetaba a mi papá.

Mi papá me buscó aquí mismo a mi mujer. Yo tenía como 20 años. Primero pidió una mujer que se llamaba Juana pero, aunque estuvo trabajando con mi mamá, a mí no me gustaba. Esa mujer no dio resultado. Yo seguí trabajando con mi papá, seguí sembrando maíz, frijol, cebolla y anís. Entonces conocí a mi mujer, a la Manuela. Ella sí me gustó y bien que ella era buena, que era para mí. Me comprometí con ella y me dio resultado. Mi papá la fue a pedir y el papá de la Manuela no dijo nada. Fue la segunda vez y tampoco dijo nada. La tercera vez dijo que sí. ${ }^{14}$

Tal vez fue mi suerte. Por eso estamos bien, bueno no tan bien pero medio, medio la estamos pasando.

Primero viví con mi papá pero tengo un hermano que nos hizo la vida imposible y me tuve que ir a lo de mi suegro y así de un lado para otro hasta que logré juntar un poco de dinero y me compré un terrenito y me puse a hacer mi casa y ya nos vinimos a vivir para acá. Después me nombraron alguacil en la municipalidad. ${ }^{15}$ Después me avisaron que necesitaban unos cinco promotores. Entonces hice mi curso de cinco semanas aquí en Guatemala, eso fue en 1985, sí tal vez sí. Y después vino una beca de los Estados Unidos y me fui tres semanas a Miami Beach en un hotel. Un hotel de esos de lujo, como los de Panajachel pero a orillas del mar. Lindo el mar también. Fuimos como 80, puros guatemaltecos. Recibimos curso de higiene personal y sobre señoras embarazadas y sobre niños desnutridos y nutridos: cómo recibir alimentos, cómo preparar suero oral... por eso yo tengo aquí en mi botiquín vendas y remedios para la lombriz... cápsulas... y así es que si mi paciente tiene vómitos yo le puedo dar suero oral para que ellos no gasten su agua del cuerpo. Porque es como una tinaja llena de agua que se quiebra y por ahí se sale el agua hasta que queda vacía... por eso mientras está agrietada hay que seguirle echando agua... Yo puedo preparar suero natural con sal... unas dos cucharitas y media y otras dos cucharitas y media de azúcar y la mitad de un limón o naranja... eso se llama suero casero. Y si tiene mal nosotros tenemos idea de cómo aliviar a las personas. Yo ya tengo como diez años de promotor. Y trabajo así en cosas de salud... cuando volví de los Estados Unidos seguí repellando mi casa. Y mi pensamiento me dijo que cuando yo esté viejo ya no podré trabajar. Mejor me voy buscando algo que trabaje sólo para mí. Y empecé a construir para hacer un hospedaje o un hotel chiquito, pues. Cosa que salga por todo unas 15

${ }^{14} \mathrm{El}$ "pedido de la novia" aún actualmente está muy codificado: los padres del pretendiente deben insistir varias veces — con discursos y regalos- antes de obtener el consentimiento de la familia de la novia.

${ }^{15} \mathrm{El}$ cargo de alguacil es una función comunitaria tradicional. Se trata del primer cargo ocupado por un joven y consiste en encargarse de mantener el orden y la limpieza en el pueblo. 
camas. Primero construyo abajo y después hago un segundo nivel. Yo tengo fe en Dios.

Así es... yo les aconsejo a la gente cómo hacer para no enfermarse pero también si ya me llegan con enfermedad trato de sacárselas, para eso tengo mi tomador de fiebre y mis pastillas para las lombrices y también tengo con qué limpiar si hay herida y con qué vendarla para que después ya no se ensucie. Así es... y para que salga mejor también tengo mis oraciones en el pensamiento. Sí... tengo mis palabras que se parecen a las de mi mamá, pero no son las mismas porque yo le pongo otras cosas ... ya no sólo oración de la antigua sino también otras palabras. Y también tengo mis piedras y ellas me dicen por dónde le entró el mal a mis enfermitos y cómo hacerle para que se le vaya... cuál es la hierbita que le va a caer bien y hasta cuántas inyecciones le conviene. Sí hasta eso me dicen mis piedras con su poder.

En esta historia de vida aparecen claramente las posibilidades -y las contradicciones - de un hombre joven que actualmente oficia de curandero y lo hace combinando diferentes prácticas: el efecto de las inyecciones se completa con el oráculo de las piedras.

El desarrollo del discurso funciona por adiciones de secuencias imprevistas que reflejan la fuerza de los referentes personales, su adaptación a situaciones móviles y, posiblemente de manera inconsciente, la evolución de nuestra relación.

El discurso se inicia con datos generales sobre su vida (infancia, búsqueda de la novia, casamiento, instalación). Datos personales pero, al mismo tiempo, compartidos con todos los hombres de la comunidad que con pocas variantes han tenido el mismo tipo de experiencia. Se trata de un discurso no comprometido que sirve de introducción a los hechos que sí considera personales: en primer término, su experiencia estadounidense y la obtención del "diploma" (encuadrado y colgado en la pared de su casa) de promotor de salud. El discurso que se refiere a estas actividades es un discurso preelaborado que incluye los terminos "científicos" que aprendió durante los cursos. La fluidez se explica porque lo repite con frecuencia para ser reconocido dentro de la comunidad y frente al exterior. Es una especie de carta de visita, una garantía de ascenso social.

Sólo al final se refiere a su práctica de la medicina tradicional, pero lo hace con titubeos y recurriendo a anáforas ("Así es...") que le permiten encontrar las palabras adecuadas. El discurso que lo asocia a las actividades de su madre implica para él un doble riesgo: por una parte, en el interior del pueblo porque muchos pacientes le tienen confianza al 
suponer que sus técnicas son "modernas" y, en consecuencia, eficaces. Por otra, frente al exterior porque puede anular la posibilidad de que un organismo nacional o internacional lo elija para ocupar alguna función o cargo que, supuestamente, modificaría radicalmente su situación económica. Eso explica reticencias y titubeos cuando se refiere al tema; incluso justifica su brevedad.

Un anciano curandero del lago Atitlán: un discurso construido que juega con los presupuestos. En San Pablo La Laguna establecimos contacto con a otro curandero, éste de 80 años de edad. Su prestigio es reconocido no sólo en su comunidad sino en toda la zona del lago y con mucha frecuencia se desplaza para atender enfermos de otros pueblos.

Una particularidad de este curandero es que ha tenido frecuentes contactos con antropólogos estadounidenses y por este motivo hace con frecuencia alusión a ellos mostrando fotos y comentando lo bien que le pagaban. Mi presencia, inevitablemente, se incluía en su antigua experiencia con las distorsiones y equívocos imaginables. Nuestra relación estaba predeterminada por circunstancias ajenas a mis proyectos y al menos a corto plazo nada podía modificarla. La actitud de don Andrés era la de un verdadero profesional en el manejo del discurso. No sólo aceptó con gusto que lo grabara, sino que además hacía interrumpir constantemente la grabación para escucharse y sólo recomenzaba si se sentía satisfecho y si todos los miembros de la familia estaban callados.

Don Andrés era un caso totalmente diferente. De Amadeo lo separaba la edad y el hecho de haber vivido su juventud y su vida de hombre maduro en circunstancias político-económicas que poco o nada tenían que ver con las actuales; había subsistido gracias al producto de sus tierras e incluso había podido acumular dinero con la venta de café. Además, aun sin saber leer ni escribir, había participado en política. Este curandero gozaba al final de su vida de un bienestar económico y de un prestigio asegurado.

Tengo 80 años y sigo trabajando con mi pom y mi candela. Antes de que me ponga más viejo le vov a enseñar a uno de mis hijos, el que está ahora en el monte. Vamos a ver si quiere porque en una de ésas no le interesa y prefiere irse a trabajar en otra cosa o seguir nomás con la tierra. Para él es más fácil porque ya tiene mis tierras donde trabajar, pero yo no tenía ni eso. Mi padre era pobre, muy pobre. Yo me acuerdo que a los 20 años me fui a la costa y me volví con un poquito de dinero y aquí me junté con mi mujer y compré un terrenito y me puse a plantar maíz, mi cebolla, mi frijol, mi café. Compré mi toro y mis gallinas y ya me fui para arriba. Estuve muy conten- 
to y le dije a mi mujer: "ahora vamos a comprar más" y así fue nomás y por eso ahora tengo mi milpa de 45 cuerdas y mucho café, frijol blanco, rojo, negro... estoy bien contento... y también siembro huisquil, ayote, banano. $\mathrm{Si}$ sobra, lo vendo, si no sobra, lo guardo sólo para mi familia. En mis terrenos hay de todo; sí, de todo. Tengo mucha tierra, por aquí y por allá más lejos. Tengo como 3000 matas de café.

Tengo como 15 hijos y más de 60 nietos y eso que algunos de los hijos se me murieron. Así siempre tengo a dónde ir para pasar momentos agradables fuera de mi casa. Voy a visitarlos, no para pedirles algo de comer sino por el gusto de visitarlos y saber cómo están. Estoy contento, sí... porque a mis hijos yo les enseñé a no robar; les enseñé a sembrar y cosechar como yo mismo hice. Eso es importante porque si uno es honesto ni el alcalde que es muy fuerte puede nada contra uno. Sí, así es... yo fui capitán del ejército en el tiempo de Ubico ${ }^{16}$ y dos veces fui juez de paz $^{17}$ y como cinco veces alcalde de cofradía. ${ }^{18}$ Cuando fui cofrade traje a los marimbistas y hasta traje el baile de la conquista. ${ }^{19}$ Gasté mucho dinero, ${ }^{20}$ pero era mi deber y lo hice contento. A pesar de todos los gastos siempre tuve de qué comer y con qué comprar la ropa y eso porque creo en Dios. Dios me ayudó y también me dio el poder para curar. Por eso cuando le digo a mi mujer: "Vamos a tomar una taza de café", tengo con qué ofrecérsela.

Antes la gente de por aquí no se enfermaba tanto, por eso nosotros con candela, con incienso y con las oraciones nos dábamos abasto. Antes la gente comía las cosas de nosotros: los pescaditos del lago y los cangrejos ${ }^{21}$ y la fruta ${ }^{22}$ y nada más que tortillas con sus frijolitos y siempre su café, pero

${ }^{16}$ Ubico fue presidente de Guatemal entre 1931 y 1944.

${ }^{17} \mathrm{El} \mathrm{juez} \mathrm{de} \mathrm{paz} \mathrm{es} \mathrm{una} \mathrm{autoridad} \mathrm{tradicional} \mathrm{encargada} \mathrm{de} \mathrm{solucionar} \mathrm{los} \mathrm{litigios}$ simples (problemas de límites de terreno entre vecinos; quejas de mujeres abandonadas por sus maridos, etcétera).

${ }^{18} \mathrm{El}$ alcalde de cofradía: es la más alta autoridad tradicional. Implica un poder religioso y político.

${ }^{19}$ La marimba es un instrumento de música: una especie de xilofono de gran tamaño. El "baile de la conquista" es un baile tradicional donde se representa, a través de los trajes, las máscaras y la danza, el encuentro de Cortés con el mundo indígena.

${ }^{20}$ Cuando una persona ocupa el puesto de alcalde de cofradía debe asumir todos los gastos de la fiesta comunitaria dedicada al santo de la cofradía. Se trata de gastos muy importantes que suelen provocar grandes desequilibrios en el presupuesto familiar $\mathrm{e}$ incluso deudas muy onerosas.

${ }^{21}$ Se hace alusión a una época pasada - hace unos 40 años-cuando se obtenían fácilmente en el lago peces pequeños y cangrejos que constituían la base de la alimentación indígena. La implantación - por orden gubernamental- de un pez de gran tamaño y muy voraz: el "black-bass" (Roccus labrax) acabó con el resto de la fauna. Por otra parte, por su gran tamaño y localización en las profundidades del lago, su pesca resulta casi imposible. Para ello es necesario un arpón y capacidades de buceador, lo que no es una característica frecuente entre la gente del lago.

${ }^{22}$ Las frutas (naranjas, bananos, etc.) existían cuando los terrenos de las orillas del lago pertenecían a los indígenas, pero desde que vendieron esas tierras y se construye- 
ahora ya no: vinieron los ladinos y trajeron esas bolsitas de papel y adentro una comida como de cartón y trajeron la coca-cola y la naranjada en las botellas y todos se empezaron a enfermar. Entonces empezamos a necesitar a esos doctores nuevos, a los que curan con inyecciones que sirven para hacer bajar las bolas de cartón que se nos hacen en los estómagos con esa comida de ahora.

Además la gente se olvidó de agradecer ${ }^{23}$ y ahora comen como perros. Ahora ya ni "buenos días" ni "buenas tardes" le dicen los hijos a sus padres. No, si ahora hasta los maltratan. Por eso vendrá el juicio final, porque ahora es puro relajo. Ya no nos hincamos frente al Presidente Dios Mundo. Ya no hay más educación y hasta la gente se mata entre ellos. Muchos ya no quieren ni el incienso ni la candela y eso fue por orden de los gringos; ellos nos mandaron a los evangélicos y a los carismáticos para que nos dijeran: "Ya no vale el Señor Jesucristo, ya no vale el Santo Mundo". Así es como hemos provocado la enfermedad, así es como nos ha llegado y ni los doctores nuevos pueden salvarnos con sus inyecciones y sus pastillas.

Antes nuestros abuelitos y nuestras abuelitas no sabían ni leer ni escribir, pero había respeto. Así es, pues... sí antes eran bien diferentes y nosotros alcanzábamos a curar a los que se enfermaban y si se morían era de puro viejos o porque les había llegado la hora pero, no como ahora, por la costumbre de darse con machetazos y hasta con balas unos contra otros o por hincharse la barriga con comida de mierdada o por andar pensando que mejor es irse con los evangélicos por lo de la salvación del alma porque todo eso es pura mentira y basta fijarse cómo, por falta de respeto al Presidente Dios, al Señor Jesucristo y al Licenciado Mundo todos se están muriendo.

En este caso el individuo hace un inventario de sus bienes económicos y de las causas de su prestigio social que asocia más a sus actividades políticas que a sus actividades como curandero. Posiblemente esto se deba al hecho de estar hablando a un extranjero y presuponiendo una jerarquía que no necesariamente es la misma cuando se comunica con gente del pueblo o con su familia. En lo que se refiere al universo terapéutico de los "nuevos doctores", se permite hacer un análisis crítico - al contrario de Amadeo, quien por su juventud intenta buscar vías complementarias - disociando el pasado del presente. Esto lo lleva a admitir que los "remedios" de antes ya no son eficaces, fundamentalmente por el nuevo tipo de alimentación que se ha introducido, por el

ron casas de veraneo, los árboles frutales desaparecieron y fue imposible su cultivo en las tierras altas sin riego.

${ }^{23}$ Don Andrés se refiere aquí a códigos muy estrictos que están asociados a la comida y que poco a poco desaparecen como es, por ejemplo, el agradecer a los padres con gestos y palabras el alimento recibido. 
abandono de las creencias tradicionales, por la violencia, etc. Finalmente concluye que ante las calamidades actuales la nueva medicina es también impotente.

La coherencia lógica de este discurso consiste en que el emisor comienza afirmando su prestigio económico y social y, una vez instaurado el sujeto de autoridad, desarrolla en la segunda parte un análisis del presente, lo que le permite terminar con una serie de conclusiones mediante fórmulas apocalípticas ("vendrá el juicio final") u observaciones lapidarias ("se están muriendo todos").

Si comparamos este discurso con los dos anteriores descubrimos una serie de diferencias que pueden atribuirse, en primer lugar, a la diferencia de edades: don Julián no podía, por su edad avanzada, adaptarse a los cambios impuestos por la medicina moderna porque no tenía los conocimientos - apenas si sabía leer y escribir- ni los medios prácticos debido a su indigencia. Amadeo, por el contrario, buscaba desesperadamente adaptarse y en parte lo lograba porque su futuro dependía de ello. El anciano don Andrés ni quería ni podía adaptarse. En segundo lugar, las diferencias de los discursos se deben a las experiencias de cada individuo, irrepetibles por únicas. En tercero, a la situación de interlocución que es determinante: las historias de vida fueron contadas a un extranjero a quien se le atribuyó un papel distinto en cada caso: para don Julián el receptor de su discurso era alguien que podía ayudarle a recuperar un papel en la sociedad; un papel social, pero también económico, dado que, al tener pocas tierras y no ocuparse regularmente de ellas, la única entrada de dinero era el pago que recibía por sus servicios de curandero; para Amadeo era alguien que podía aportarle, sobre todo, beneficios materiales (remedios, instrumentos médicos, clientes para su futuro hospedaje, comisión por la venta de un terreno, etc.); para don Andrés - hombre consciente de estar al final de su vida- era un auditorio ante quien probar un prestigio (económico, político y social) ya adquirido. Él no buscaba el reconocimiento sino la confirmación de lo bien fundado de sus decisiones y logros. Él no tenía proyectos, como era el caso de los otros dos curanderos y, en realidad, no esperaba nada concreto de su interlocutor. El interlocutor para él ocupaba sólo el lugar de un auditorio atento y admirativo. En última instancia, contaba lo que a él le gustaba escuchar.

Otro factor importante que quisiéramos destacar y que depende también de la situación de interlocución es el de los presupuestos que resultan proporcionales a la importancia de la relación interpersonal: cuando don Julián me contó "su vida", ya hacía años que nos conocíamos, lo cual ex- 
plica que su discurso fuera extremadamente sintético y elíptico; podía seleccionar una etapa de su vida porque presuponía que del resto yo ya estaba al corriente.

El discurso de Amadeo no es elíptico: él intenta abarcar varias etapas, pero si lo hace en forma adicional es, en parte, presuponiendo que si me habla de "eso" es porque sabe que también me interesa, tanto o más que lo que me contó anteriormente. Sus palabras presuponen que todavía no nos conocemos bastante y no sabe muy bien qué estoy buscando ni qué debe contarme. Ese titubeo temático refleja nuestras relaciones vacilantes: cada encuentro en el lapso de tres años nos hizo cambiar la opinión que teníamos uno del otro. Como consecuencia, variaban nuestras estrategias y aumentaban nuestras dudas sobre la fiabilidad del otro.

El discurso de don Andrés se basa también en presupuestos pero no de carácter personal sino contextual (situación política, económica y social de los pueblos del lago), lo que nos obliga a incluir muchas notas en su discurso para aclarar referencias. Sin embargo, en lo que se refiere a su vida el relato no omite elementos importantes ni precisiones (número de hijos, tamaño de sus terrenos, puestos políticos ocupados, etcétera). Esta expansión narrativa, así como la organización cronológica de su discurso, se explica en parte por su deseo de informarme; supone que apenas lo conozco y efectivamente así era en el momento de la entrevista.

\section{Esbozos de conclusión}

Un camino parece imponerse a esta altura de la interpretación: La decodificación de las historias de vida es imposible desde una perspectiva "inmanentista". El contenido de estos dicursos se actualiza en circunstancias enunciativas; grabados o escritos, están privados de elementos indispensables para su comprensión. Los ejemplos que he citado prueban hasta qué punto la situación de interlocución determina lo que se quiere decir y, sobre todo, lo que se quiere callar: si don Julián se concentró en su experiencia iniciática haciendo abstracción del presente alienante que vivía, fue para actualizar un pasado que le servía como prueba de sus conocimientos y medio para reivindicar lo que él consideraba como sus derechos. Por otra parte, se trataba de un narrador de extraordinarias cualidades y además habituado a un trabajo de registro y transcripción de historias. El conocimiento de este tipo de retórica discursiva influyó en la "construcción" de su discurso, y ello con la finalidad de crear una representación heroica de sí mismo. 
La contraparte real de su historia nos resultaría desconocida sin la intervención de su mujer, que por casualidad estaba presente ese día.

La historia de Amadeo se organizó en enunciados relacionados unos con otros, sin llegar a obtener una coherencia narrativa. Una presentación abierta a nuevas secuencias, como lo es su propia existencia, que oscila constantemente entre dos mundos dispares y muchas veces contradictorios. Sus palabras reflejan el intento de combinaciones imprevisibles entre lo tradicional y lo moderno; intento donde se incluye una improbable conciliación entre lo que él cree ser y lo que él cree que yo pienso que es.

La historia de don Andrés es total y cerrada: cada secuencia transita naturalmente a otra, lo que permite comprobar un avance en la argumentación. Sus estrategias discursivas, como las otras dos, se inscriben en una situación de conflicto determinada por los cambios que se han producido en los últimos 40 años y que han marcado una división tajante entre dos universos cognoscitivos: por un lado, los que siguen la vía del "progreso"; por otro, los que se aferran a los conocimientos tradicionales. Él ha optado; ya no tiene tiempo ni intenciones de cambiar. Seguro de sí, es posible que haya sido el único que no se interesó en saber cuál era mi intención. Quizá porque al final de su vida había comprendido que no podía esperar nada del exterior.

La duda persiste. Las perspectivas no van más allá de acercarnos a representaciones de una realidad que permanece subjetiva, y en consecuencia esencialmente inaccesible. Figuras de un calidoscopio: el otro y sus palabras, sus gestos, su visión del mundo, y de nosotros, fugazmente incluidos en ese mundo. En cada movimiento, las combinaciones son diferentes; el sentido de las figuras, otro.

¿Admitir entonces que nuestro papel de intérpretes se reduce a una aventura de aproximación pocas veces certera y que, por lo general, nos limitamos a elaborar "simulaciones de realidad", prismas deformados donde nuestra lógica se debate sin sentido contra la dinámica de alguien a quien pretendo haber comprendido en el lapso -indefectiblemente limitado y circunscrito- de mi presencia?

\section{Bibliografía}

ANSART, Pierre

1990 Les sociologies contemporaines, Point-Seuil, París.

Auge, M.

1994 Le sens des autres, Fayard, París. 
BARDIN, Laurence

1977 L'analyse de contenu, PUF, Col. Le Psycologue.

CASSIRER, Ernest

1972 La philosophie des formes symboliques. 1. Le langage, Les Editions de Minuit, París.

Chutz, Alfred

1987 Le chercheur et le quotidien, Meridiens Klincksiek, París.

CoSNIER, J., y C. Kerbrat-Orecchioni

1987 Décrire la conversation, Presses Universitaires de Lyon, Lyon.

De Certau, Michel

1989 L'invention du quotidien, I, Arts de Faire, 10/18, 1980, París.

Kerbrat-Orecchioni, Catherine

1986 L'implicite, Armand Colin, París.

NAMER, G.

1987 Mémoire et Societé, Meridiens Klincksiek, París.

Poirier, J., S. Clapier-Valadon, P. Rambaut

1983 Les récits de vie. Théorie et pratiques, PUf, París.

UNRUG, M. C.

1974 Analyse de contenu et acte de la parole, Delarge (Ed. Universitaires), París. 